\title{
A survey of British Columbia anesthesiologists on a provincial critical incident reporting program
}

\author{
[Une enquête auprès des anesthésiologistes de la Colombie-Britannique sur un
}

programme provincial de notification des incidents critiques]

Richard N. Merchant MD FRCPC, Patricia M. Gully BA MLIS

Purpose: To determine why British Columbia's anesthesiologists have not actively participated in a provincial Critical Incident Reporting Service by submitting reports of critical incidents experienced in their practice.

Methods: An email and postal mail survey of $\mathrm{BC}$ anesthesiologists was undertaken, proposing a variety of reasons why critical incidents may not be reported to the Service.

Results: 207 responses were received from 368 specialist and general practitioner anesthesiologists. Respondents indicated general satisfaction with the overall concept of having an incident reporting service, and with the design of the multi-page reporting form. The greatest perceived problems to reporting incidents were related to aspects of workload, fear of litigation or a record of problems, and difficulties with the terminology of incident and error reporting. There are implications to the establishment of broader based programs in Canada.

Conclusion: A number of factors are responsible for under reporting of critical events. Further efforts to encourage reporting are required.

Objectif : Déterminer pourquoi les anesthésiologistes de la ColombieBritannique n'ont pas activement participé au Service provincial de notification des incidents critiques en soumettant des rapports d'incidents vécus dans leur pratique.

Méthode : Une enquête a été envoyée par courrier postal et électronique aux anesthésiologistes de la CB et proposait diverses raisons pour expliquer pourquoi les incidents critiques n'étaient pas rapportés au Service.

Résultats : Parmi les 368 anesthésiologistes spécialistes et généralistes sondés, 207 ont répondu. Ils ont indiqué une satisfaction générale quant au concept global de service de notification d'incident et au formulaire multipage utilisé. Les plus grands problèmes perçus face à la notification des incidents étaient reliés à la charge de travail, à la peur de litige ou de dossier de problèmes et aux difficultés avec la terminologie de notification d'incident ou d'erreur. II y a des implications à l'établissement de programmes largement applicables au Canada.

Conclusion : Un certain nombre de facteurs sont responsables du peu de notification des incidents critiques. II faut des efforts supplémentaires pour encourager la notification.

7 HERE is currently a great deal of interest in critical incidents, complications, and errors in medicine. This is evidenced in both the lay press and professional publications, and in the development of government and professional organizations tasked to evaluate the scale of the problem and develop solutions.

As part of a quality improvement program of the British Columbia Anesthesiologists' Society (BCAS), the Society has sponsored a Critical Incident Reporting Service (CIRS) program since 1997, following the then well-established Australian model, the Australian Incident Monitoring Study. ${ }^{1}$ Our program, initiated by the Executive Board of the association, was introduced to members and received vocal support at several general meetings. Details of the program, and forms on which critical incidents could be reported, were then introduced and circulated to chiefs of anesthesia departments in BC hospitals with bed counts greater than 35 . Critical incidents were to

From the Department of Anesthesia, the Royal Columbian Hospital, New Westminster; and the British Columbia Anesthesiologists' Society, British Columbia, Canada.

Address correspondence to Dr. Richard N. Merchant, Department of Anesthesia, the Royal Columbian Hospital, 330 Columbia St. E, New Westminster, B.C. V5E 3W7, Canada. E-mail: richard.merchant@ubc.ca

Dr. Merchant is the Chairman of the Patient Safety Committee and Ms. Gully is the executive assistant of the British Columbia

Anesthesiologists' Society.

Accepted for publication January 17, 2005.

Revision accepted March 29, 2005. 
be reported anonymously on forms which were mailed to the association secretary, and entered into a secure database. The form was modified several times in response to feedback, and subsequently an internetbased data entry form was introduced.

We have not been satisfied with the success of this program, as measured by the limited reporting of incidents to the service. By March 2005, a total of only 137 incidents had been reported. To ascertain reasons for this lack of involvement, and to distinguish between problems with the reporting form itself $v s$ the critical incident analysis process, we undertook a survey of BC anesthesiologists on critical incident reporting in general, and our program, specifically.

\section{Methods}

In the spring of 2004 a questionnaire ${ }^{\mathrm{A}}$ was developed, both in paper form and via a database accessible on the internet. Questions were designed to elicit reasons why members might not identify and submit incidents, complications, or problems to the reporting database. We asked eight general and demographic questions, and proposed 24 statements about critical incident reporting in which respondents were instructed to quantify the level of their agreement on a seven-point scale, from "absolutely disagree" to "completely agree". Respondents were allowed to provide an identifying number which allowed further demographic analysis: giving this number was voluntary, though anonymity was assured.

The survey instrument was tested within the executive of the BCAS and refined. Surveys were then distributed to 368 active (fellowship anesthesiologists) and associate (primarily family physician/anesthesiologists) BCAS members. The survey was circulated via email to those with email addresses (312) and via paper mail to those without (56); and a total of three reminder messages were sent via email in follow-up. Reports could be submitted in paper form or through a web-based data form on the BCAS website: both methods were used by respondents and were not analyzed separately. There were a few submissions with duplicate identification numbers: the initial submission was used and the second deleted. Data was stored and descriptive statistical analysis was done using Microsoft Excel 2003®.

Data were analyzed according to the primary categories of "agree", "indifferent", "disagree", or no response, and addressed the following broad cate-

A The survey document is accessible at www.bcaswebsite.ca/index.php? page =safety.

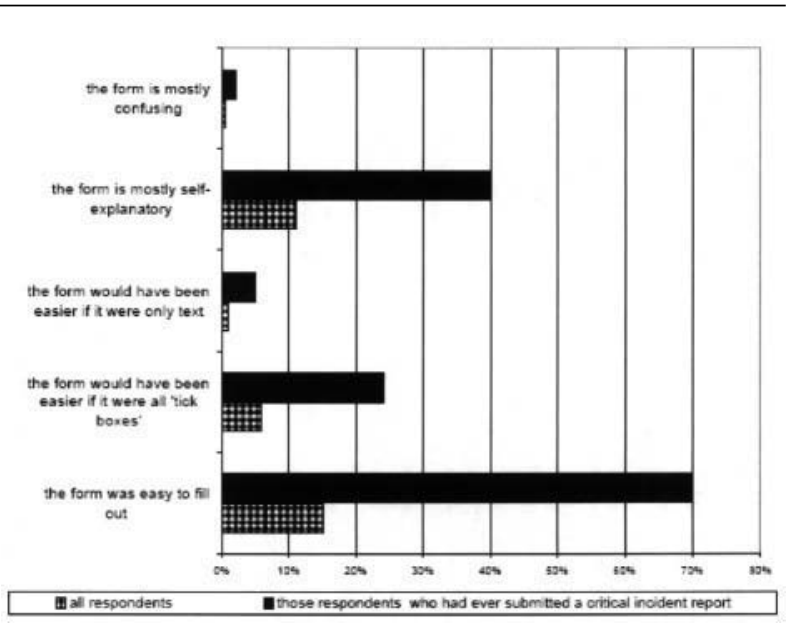

FIGURE 1 Five questions proposing specific features about the Critical Incident Reporting Service (CIRS) form, with respondents who had actually filled and submitted a CIRS form compared to all respondents.

gories: problems with the actual reporting form itself; inaccessibility of the reporting form; lack of familiarity with the program and the critical incident analysis process; concerns that information from the form might be misused; feelings that the process was lacking in value; and other miscellaneous reasons for nonsubmission.

\section{Results}

Reports were received from 207 individuals, for an overall response rate of $56 \%$. Forty respondents (19\%) did not provide an identification number which allowed further demographic analysis; if these individuals were distributed in the same fashion as those who did, then approximately $56 \%$ of fellowship, and $62 \%$ of associate members responded.

As only $20 \%$ of respondents to the survey had actually submitted a form reporting a critical incident, the responses to six specific questions regarding the CIRS form are divided on this basis in Figure 1.

While overall, only $15 \%$ reported positively that "the form was easy to fill out," $70 \%$ of those who had actually submitted a CIRS form ${ }^{B}$ reported positively to this question. Six percent of respondents preferred a form with "all tick boxes," $11 \%$ felt there were "too

B The BCAS CIRS form is a six-page pamphlet, one of free text, $31 / 2$ pages of tick-box entry, and one of definitions and explanations. There is also a one-page "short form". Both can be viewed at www.bcaswebsite.ca/index.php?page=safety. 


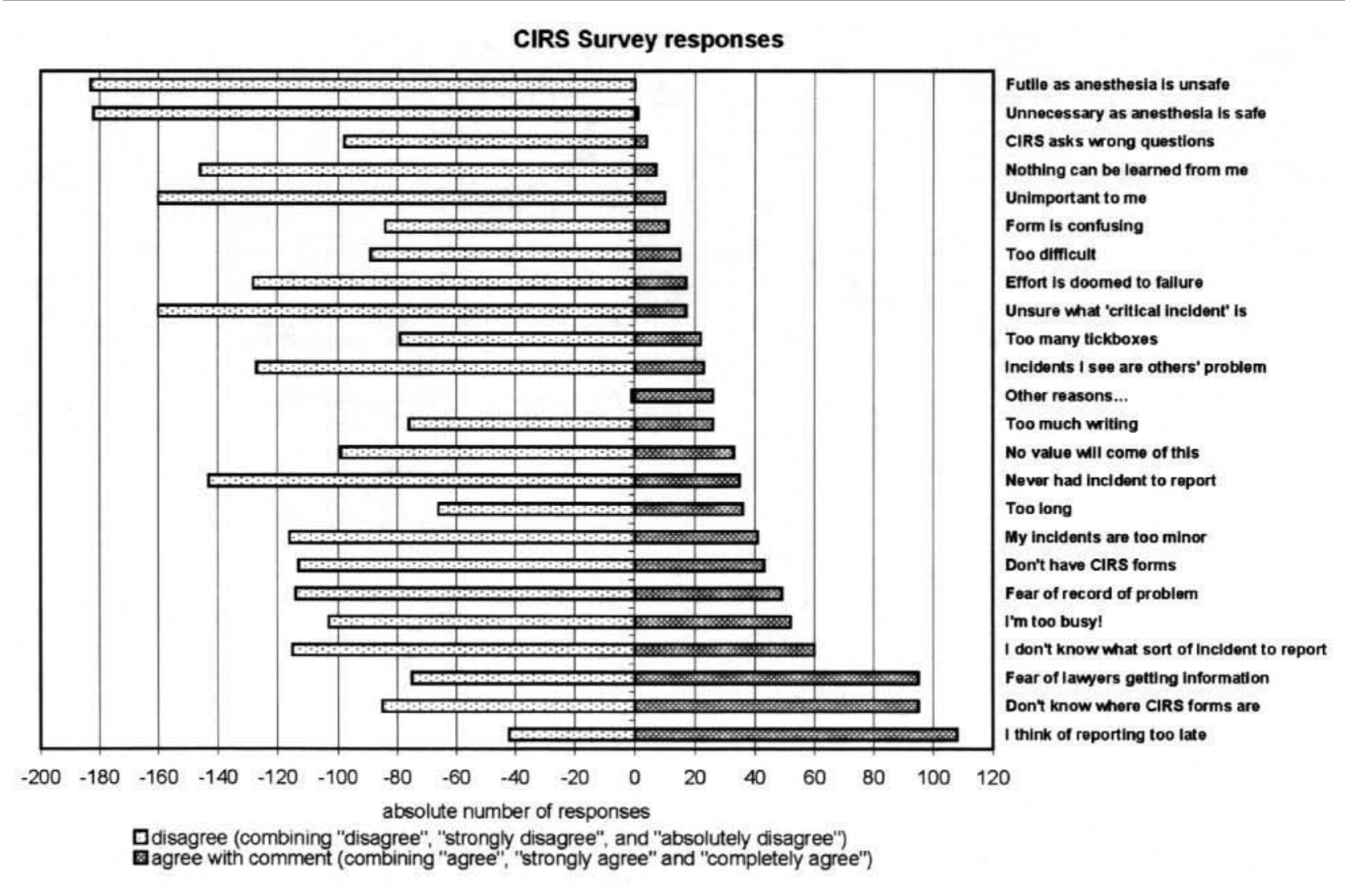

FIGURE 2 Responses to 23 statements proposing various philosophical and practical barriers to reporting critical incidents to the Critical Incident Reporting Service program.

many ticks," but only $1 \%$ preferred "only text" while $13 \%$ thought there was "too much writing." Only $17 \%$ felt the form to be "too long."

Lacking ready availability of forms may preclude incident reporting. Twenty-one percent of members thought they did not have forms in their hospitals, and $46 \%$ didn't know where they were, despite distribution to all $\mathrm{BC}$ hospitals on two occasions, to individuals on several occasions, access via the internet, and repeated advertising.

British Columbia has a provincial Evidence $\mathrm{Act}^{2}$ with regulations promulgated which specifically protect the CIRS program from legal disclosure. This has been communicated in detail to members on many occasions. Despite this, $46 \%$ of respondents reported concern about lawyers getting hold of the information, and $24 \%$ expressed fear of there being a "record of problems."

Definition of terms is a problem worldwide. ${ }^{3}$ While only $8 \%$ of respondents were "unsure what a critical incident is," $17 \%$ claimed that they "never had an incident to report" and $29 \%$ were "unsure what to report." Twenty-five percent of respondents felt that they were "too busy" to report problems.

In a free-text response field, six respondents commented upon their institution having 'mortality and morbidity' or 'quality assurance' committees, whose activities involve the analysis of critical incidents in their institutions. This valuable activity allows institutions to analyze specific incidents in depth, but does not serve the goal of collecting information on a system-wide basis. It seems likely that individuals are less likely to report to two separate programs, though we did not address this question directly.

Despite these concerns and the general lack of overt involvement from members, only $8 \%$ felt the program was "doomed to failure," $5 \%$ felt it "unimportant to me," $0 \%$ "unnecessary" and $0 \%$ "futile."

\section{Discussion}

The key findings of the survey were the relative satisfaction of respondents with the design of the CIRS form, and the apparent belief in the value of the criti- 
cal incident reporting process, but that barriers to reporting included fear of liability ramifications, issues with language or terminology, and the unwillingness or inability to take the time to report incidents.

Successfully establishing a voluntary, multi-institution program for reporting incidents and/or errors in medical practice depends upon a number of factors. Individual clinicians must be motivated to analyze their practice in this fashion, and there must be no barriers to doing this in terms of perceptions of legal liability, professional criticism, or other misuse of the information. Furthermore, there must be sufficient time to undertake the effort, and ready access to an adequately designed reporting form or instrument.

The reporting form or service must be accessible and acceptable to all: designing a form which is universally satisfactory is a challenge. We modelled our reporting form and the questions by adhering to previously defined models, primarily (with his permission) the internet-based critical incident reporting survey form utilized by Dr. Sven Staender on the Swiss Anaesthesia Server/University of Basel website, ${ }^{\mathrm{C}}$ which itself was modelled on the Australian AIMS report. ${ }^{\mathrm{D}}$

While one will never find a form acceptable to all individuals, we are encouraged by the fact that $70 \%$ of respondents who had reported an incident found the form 'easy to fill out'. This finding may, of course, reflect a self-selected group of particularly motivated participants, and may not be generally applicable to anesthesiologists as a whole. In any case, there was not a significant criticism of specific points of our mixed text/tick-box form.

The problem with common terminology of 'events,' 'incidents,' 'accidents', and so on is being addressed by the Royal College of Physician and Surgeons of Canada with the 'Patient Safety Dictionary', ${ }^{4}$ and by other organizations including the Canadian Anesthesiologists' Society through participation in a 'data dictionary' project to define common terms. Whether this will translate fluidly to facilitate the practice of clinicians remains to be seen.

We were encouraged by the small number of respondents who rejected the program in general. We established the program through enthusiasm at the BCAS executive, not following a 'grass roots' demand. Runciman, ${ }^{5}$ in contrast, described the establishment of the now successful Australian program, noting that "in

\footnotetext{
C This form has subsequently been modified. The modified version can be viewed at http://www.anaesthesie.ch/cirs/ (accessed November 11, 2004).
}

D Personal communication, Dr. Jan Davies.
May 1987 about 60 influential Australian clinicians were invited to a meeting on monitoring and patient safety at which it was decided to set up the Australian Patient Safety Foundation..." This may emphasize the utility of getting widespread membership involvement prior to, or coincident with, the establishment of a new program.

Lawton and Parker ${ }^{6}$ described a system of reporting by third parties in which they found reluctance to report adverse events to a superior. They felt that "some cultural change may be necessary in the National Health Service before either the informal reporting studied here, or a more formal incident reporting system can work optimally."

Similarly, Sanborn et al. ${ }^{7}$ reviewed automatically recorded anesthetic charts and found that, in a group of 434 intraoperative incidents representing deviations from norms previously defined to be relevant quality assurance (QA) indicators in their hospital department, only $4.1 \%$ of incidents had been reported to the QA system. Significantly, they also noted a "strong association between intraoperative incidents and inhospital mortality."

We believe that the process of recognizing, analyzing, and reporting critical incidents is a valuable tool to improve one's clinical practice. However, from this data and our clinical experience, we conclude that to successfully establish a formal program of this nature, a culture change may be necessary in BC and Canada. The actual format of a reporting form has received a great deal of attention, but may not be a critical variable in achieving successful reporting programs. A supportive legal environment, such as that provided by British Columbia's legislation on evidence, does not appear to be uniformly recognized by clinicians. Rather, solving more practical logistical issues may improve compliance, but be more difficult to achieve. Worldwide, physicians report increasing stress and workloads, and in BC, many departments of anesthesia are searching for staff. Unlike Australia and New Zealand, most departments do not have anesthesia assistants in the operating rooms effectively reducing clinician workloads. The reports of "I'm too busy" and "I think of reporting too late" may reflect these systemic problems, and are not obviously amenable to change by enthusiasts and national organizations promoting incident and error reporting programs.

The BCAS will continue to promote our members' involvement with our critical incident reporting program through continuing education of members regarding availability of the program, and the legal aspects of the program operating in British Columbia. 


\section{Acknowledgements}

The authors thank those anesthesiologists of British Columbia who participated in the BCAS Critical Incident Reporting Service and supported the CIRS Survey with their contributions.

\section{References}

1 Webb RK, Currie M, Morgan CA, et al. The Australian Incident Monitoring Study: an analysis of 2000 incident reports. Anaesth Intensive Care 1993; 21: 520-8.

2 Statutes and Regulations of British Columbia Evidence Act [RSBC 1996 Chapt 124]. Available from URL; http://www.qp.gov.bc.ca/statreg/stat/E/96124_01.h tm.

3 Dovey SM, Phillips RL. What should we report to medical error reporting systems? Qual Saf Health Care 2004; 13: 322-3.

4 Davies JM, Hébert P, Hoffman C. The Canadian Patient Safety Dictionary. Ottawa: Royal College of Physicians and Surgeons of Canada; 2003. Available from URL; http://rcpsc.medical.org/ publications/PatientSafetyDictionary_e.pdf (accessed Nov 12, 2004).

5 Runciman WB. Lessons from the Australian Patient Safety Foundation: setting up a national patient safety surveillance system-is this the right model? Qual Saf Health Care 2002; 11: 246-51.

6 Lawton R, Parker D. Barriers to incident reporting in a healthcare system. Qual Saf Health Care 2002; 11 : 15-8.

7 Sanborn KV, Castro J, Kuroda M, Thys DM. Detection of intraoperative incidents by electronic scanning of computerized anesthesia records: comparison with voluntary reporting. Anesthesiology 1996; 85: 977-87. 